\title{
Process Parameters Optimization for Friction Stir Welding of Pure Aluminium to Brass (CuZn30) using Taguchi Technique
}

\author{
O. M. R. Elfar ${ }^{1, a}$, R. M. Rashad ${ }^{1}$ and H. Megahed ${ }^{1}$ \\ ${ }^{1}$ Department of Mechanical Designand Production Engineering, Faculty of Engineering, Cairo University, Egypt
}

\begin{abstract}
In this research, the friction stir welding of dissimilar commercial pure aluminium and brass (CuZn30) plates was investigated and the process parameters were optimized using Taguchi L9 orthogonal array. The considered process parameters were the rotational speed, traverse speed and pin offset. The optimum setting was determined with reference to ultimate tensile strength of the joint. The predicted optimum value of ultimate tensile strength was confirmed by experimental run using optimum parameters. Analysis of variance revealed that traverse speed is the most significant factor in controlling the joint tensile strength and pin offset also plays a significant role. In this investigation, the optimum tensile strength is $50 \%$ of aluminium base metal. Metallographic examination revealed that intermetallic compounds were formed in the interface of the optimum joint where the tensile failure was observed to take place.
\end{abstract}

\section{Introduction}

Many applications in auto-mobile, aero-space, power generations and military purposes need to join dissimilar metals. Using conventional fusion methods are not preferred for dissimilar jo ining because of solidification defects and intermetallic compounds (IMCs) formations. Therefore, the solid-state joining methods have received much attention for this purpose. Friction stir weld ing (FSW) is a revolutionary solid-state joining process patented at The Welding Institute (UK) in 1991. The joining process proceeds in a solid-state where temperature during welding is relatively less than the melting point of base metals. Friction Stir welding process is based on a quite simple concept: a nonconsumable rotating welding tool is plunged into adjoining parent metals. The heat generated by the friction between the tool shoulder and weld metal during this process makes the surrounding metals around the tool soft and causes local plastic deformation. The softened metals are stirred together by the rotating tool pin resulting in a solid state bond. FSW minimizes or eliminates defects caused by melting, such as, impurities, porosity, solidification cracks and (IMCs) formation. [1]

\subsection{FSW parameters}

FSW improper process parameters cause abnormal metal flow or imp roper heat input that lead to defective weld ing. Therefore, the effect of process parameters on weld mechanical properties and microstructure evolution is attractive topics for researchers [2]. The following is list of FSW process parameters:

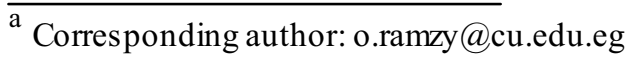

1. Rotational speed

2. Traverse speed

3. Pin offset

4. Axial force

5. Tool geometry

A. Es maeili et al. [3] investigated the effect of rotational speed and pin offset on the dissimilar FSW joint of aluminium 1050 to brass and a sound joint was success fully performed at rotational speed and pin offset of $450 \mathrm{rpm}$ and $1.6 \mathrm{~mm}$ to aluminium respectively. The sound joint structure at the nugget zone of aluminium was made of a composite structure, consisting of brass particles and intermetallic, especially at the upper region of the weld cross section. Also P. Xue et al. [4] investigated the effect of rotational speed and pin offset on mechanical properties and microstructure of the dissimilar FSW joint of aluminium 1060 to pure copper. The sound joint with $110 \mathrm{MPa}$ ultimate tensile strength (UTS) (84.6\% of Al base metal) was produced at 600 rpm rotational speed and $2 \mathrm{~mm}$ pin offset to aluminium.

C.W. Tan et al. [5] studied the effect of the traverse speed on appearance, microstructure and formation mechanism, and mechanical properties of 5A02 FSW aluminium alloy - pure copper joint and the results revealed that At traverse speed of $40 \mathrm{~mm} / \mathrm{min}$, cavity defect was observed in the cross-sectional macrograph indicating incomplete mixing between $\mathrm{Al}$ and $\mathrm{Cu}$. Th is defect was usually as sociated with insufficient metal flow caused by insufficient heat input. At traverse speed of 20 $\mathrm{mm} / \mathrm{min}$, the proper mixing occurred and void-free joint was obtained with tensile strength of $130 \mathrm{MPa}$ representing joint efficiency of $75.6 \%$ of the Al alloy base metal. 
Aluminium and brass widely in industries, especially in sheet metal forming processes. Fusion welding of these metals is not possible because of solidification defects and intermetallic compounds (IMCs) formations. Practically, researches in FSW of these metals are rare especially those used Taguchi optimization technique. In this investigation, an attempt is made to investigate process parameters such as rotational speed, traverse speed and pin offset on FSW of aluminium and brass. The levels and values of process parameters are listed in Table 1.

\subsection{Taguchi Method}

Taguchi method is a good problem solving tool, which can upgrade/improve the performance of the product, process, design and system with a significant minimizing in experimental time and cost. Further, by using this technique, the most influential parameters can be determined in the overall performance. The optimum process parameters obtained from the Taguchi method are not sensitive to the variation in environmental condition and other noise factors. The Taguchi method uses a special design of orthogonal array to study the entire process parameter space with a small number of experiments only. With the increase of process parameters, the number of experiments increases. Taguchi proposed a three-step Approach [6]:

1. System design

2. Parameter design

3. Tolerance design

In system design, the engineer applies scientific and engineering knowledge to produce a basic functional prototype design. The objective of parameter design is to optimize the settings of the process parameter to improve quality characteristics. In addition, it is expected that the optimal process parameter values obtained from parameter design are insensitive to variation and other noise factors. Tolerance design is used to determine and analyse tolerances around the optimal settings recommend by the parameter design. Tolerance design is required if the reduced variation obtained by the parameter design does not meet the required performance, and involves tightening tolerances on the product or process parameters for which variations result in a large negative influence on the required product performance. Steps of Taguchi parameter design are following [2, 6]:

Step 1: Selection of factors to be evaluated.

Step 2: Selection of number of levels for each factor.

Step 3: Selection of the appropriate orthogonalarray.

Step 4: Conduct the experiments.

Step 5: Analyse the data and determine optimum levels for control factors.

Step 6: Confirmation experiment.

The selection of which orthogonal array to use depends on the following $[2,6]$ :

1. The number of factors and interactions of interest.

2. The number of levels for the factors of interest.

As three factors and three levels are selected, $\mathrm{L}_{9}$ orthogonal array (OA) is used in this investigation. Only the main factor are taken into consideration and not the interactions. The chemical composition and mechanical properties of the plate are given in Tables 2 and 3.

Table 1. Assignment of levels to control factors.

\begin{tabular}{|c|c|c|c|c|}
\hline & & Level 1 & Level 2 & Level 3 \\
\hline \multirow{3}{*}{$\begin{array}{l}\text { Control } \\
\text { Factors }\end{array}$} & $\begin{array}{c}\text { Rotational } \\
\text { speed (rpm) }\end{array}$ & 173 & 350 & 555 \\
\hline & $\begin{array}{l}\text { Traverse } \\
\text { speed } \\
(\mathrm{mm} / \mathrm{min})\end{array}$ & 11 & 14 & 18 \\
\hline & $\begin{array}{l}\text { Pin offset } \\
(\mathrm{mm})\end{array}$ & 0.5 & 1.0 & 1.5 \\
\hline
\end{tabular}

Table 2. Assignment of levels to control factors.

\begin{tabular}{llll}
\hline \multicolumn{4}{c}{ Aluminium } \\
\hline Element & Al & Fe & Others \\
Percentage & Balance & 0.387 & 0.418 \\
\hline \multicolumn{4}{c}{ Brass } \\
\hline Element & $\mathrm{Cu}$ & $\mathrm{Zn}$ & Others \\
Percentage & 68.888 & 30.723 & 0.389 \\
\hline
\end{tabular}

Table 3. Mechanical properties of base metals

\begin{tabular}{llll}
\hline Base metal & $\begin{array}{l}0.2 \% \text { Proof } \\
\text { strength } \\
(\mathrm{MPa})\end{array}$ & $\begin{array}{l}\text { Ultimate } \\
\text { tensile strength } \\
(\mathrm{MPa})\end{array}$ & $\begin{array}{l}\% \\
\text { Elongation }\end{array}$ \\
\hline Aluminium & 81 & 106 & 3.5 \\
Brass & 633 & 697.6 & 2.1 \\
\hline
\end{tabular}

\section{Experimental Procedure}

The materials used in this investigation are commercial pure aluminium and brass $(\mathrm{CuZn} 30)$. Both metals are received as fully rolled plate with $5 \mathrm{~mm}$ in thickness. The received base metals were cut to square plates of $100 \mathrm{~mm}$ in width. Traditional milling machine was used to produce the FSW jo ints. Brass plate was fixed in the advanced side. FSW tool was made of heat treated Bohler K340 cold work tool steel with shoulder diameter of 20 $\mathrm{mm}$, tapered pin with $5-4 \mathrm{~mm}$ in diameter and $4.85 \mathrm{~mm}$ in length and hardness of $57 \mathrm{HR}_{\mathrm{C}}$. The experiments were performed using $\mathrm{L}_{9}$ orthogonal array (OA). The selected process parameters are rotational speed, traverse speed and pin offset.

The tensile tests are conducted on three traverse flat tension test specimens for each condition according to ASTM E 8M Standard [7] on a universal testing machine. Fig. 1 represents the flat tensile test specimen dimensions. The ultimate tensile strengths were determined for each specimen. Table 4 illustrates the designed experimental layout values. Vickers Hardness test is conducted across the welding line of the optimum joint using a load of 1 $\mathrm{Kg}$ and test force retaining time of 30 seconds. Metallographic examinations using both the optical microscopy (OM) and Scanning Electron Microscopy (SEM) are performed on the optimum jo int cross section which is perpendicular to the weld line. 


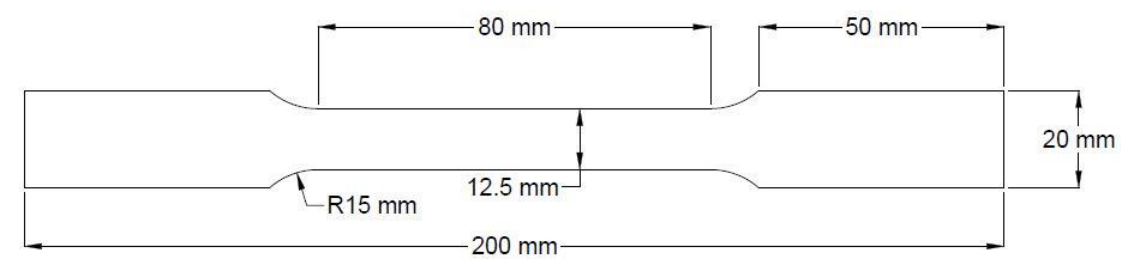

Figure. 1 Flat tensile test specimen dimensions.

\section{Results and discussion}

\subsection{Analysis of tensile test results}

For each experimental condition, three tensile test trials are conducted and three ultimate tensile strength values (responses) are determined. For analysis of the results, $\mathrm{S} / \mathrm{N}$ ratios and mean values are calculated for each condition and are illustrated in table 4 . The $\mathrm{S} / \mathrm{N}$ ratio is calculated based on the quality of the characteristics intended. The higher the better $\mathrm{S} / \mathrm{N}$ ratio is calculated because the objective function of this investigation is to maximize the tensile strength.

The average mean and $\mathrm{S} / \mathrm{N}$ ratio values for each level of each parameter are calculated and illustrated in tables 5 and 6 . The main effects for mean and $\mathrm{S} / \mathrm{N}$ ratio are plotted in Fig. 2 and 3. Based on mean values the optimal level setting is $\mathrm{A}_{2} \mathrm{~B}_{1} \mathrm{C}_{2}$ and based on $\mathrm{S} / \mathrm{N}$ ratio the optimal level setting is $\mathrm{A}_{1} \mathrm{~B}_{1} \mathrm{C}_{2}$.

Analysis of Variance (ANOVA) is performed for mean and $\mathrm{S} / \mathrm{N}$ ratio. The aim of ANOVA is to determine the significant process parameters and level of confidence of them. The ANOVA table for mean and $\mathrm{S} / \mathrm{N}$ ratio are calculated and listed in tables 7 and 8 . Tabulated $F$ values are listed at table 9. In this investigation, the analys is based on the mean revealed that the traverse speed and the pin offset are significant factors at confidence levels of $95 \%$ and $90 \%$ respectively, and the analysis based on $\mathrm{S} / \mathrm{N}$ ratio revealed that the traverse speed and the pin offset are significant factors at confidence levels of $99 \%$ and $95 \%$ respectively. As the rotational speed is not significant factor as revealed from the both analyses; the analysis based on $\mathrm{S} / \mathrm{N}$ ratio and the analysis based on mean, the optimum setting revealed from analysis of mean is selected and the level 2 of rotational speed factor (350 rpm) is considered the optimal setting in this work.

Table 4. Assignment of levels to control factors.

\begin{tabular}{cccccc}
\hline \multirow{2}{*}{$\begin{array}{c}\text { Run } \\
\text { no. }\end{array}$} & $\begin{array}{c}\mathbf{A} \\
\text { Rotational } \\
\text { speed }\end{array}$ & $\begin{array}{c}\text { Control factor } \\
\text { Traverse } \\
\text { speed }\end{array}$ & $\begin{array}{c}\text { C } \\
\text { Pin } \\
\text { offset }\end{array}$ & $\begin{array}{c}\text { UTS } \\
\text { Mean } \\
\text { (MPa) }\end{array}$ & $\begin{array}{c}\text { UTS } \\
\text { S/N } \\
\text { ratio } \\
\text { (dB) }\end{array}$ \\
\hline 1 & 1 & 1 & 1 & 44.75 & 33.01 \\
2 & 1 & 2 & 2 & 26.84 & 28.57 \\
3 & 1 & 3 & 3 & 26.53 & 28.47 \\
4 & 2 & 1 & 2 & 52.55 & 34.39 \\
5 & 2 & 2 & 3 & 16.00 & 23.93 \\
6 & 2 & 3 & 1 & 34.31 & 30.70 \\
7 & 3 & 1 & 3 & 30.81 & 29.64 \\
8 & 3 & 2 & 1 & 21.93 & 26.78 \\
9 & 3 & 3 & 2 & 38.20 & 31.64 \\
\hline
\end{tabular}

Table 5. Average mean values for each level of control factors.

\begin{tabular}{cccc}
\hline \multirow{2}{*}{ Level } & A & B & C \\
\cline { 2 - 4 } & $\begin{array}{c}\text { Rotational } \\
\text { speed }\end{array}$ & $\begin{array}{c}\text { Traverse } \\
\text { speed }\end{array}$ & Pin offset \\
\hline 1 & 32.70 & $\mathbf{4 2 . 7 0}$ & 33.66 \\
2 & $\mathbf{3 4 . 2 8}$ & 21.59 & $\mathbf{3 9 . 2}$ \\
3 & 30.31 & 33.01 & 24.45 \\
\hline
\end{tabular}

Table 6. Average $\mathrm{S} / \mathrm{N}$ ratio values for each level of control factors.

\begin{tabular}{cccc}
\hline & A & B & C \\
\cline { 2 - 4 } Level & $\begin{array}{c}\text { Rotational } \\
\text { speed }\end{array}$ & $\begin{array}{c}\text { Traverse } \\
\text { speed }\end{array}$ & Pin offset \\
\hline 1 & $\mathbf{3 0 . 0 2}$ & $\mathbf{3 2 . 3 5}$ & 30.16 \\
2 & 29.67 & 26.42 & $\mathbf{3 1 . 5 4}$ \\
3 & 29.39 & 30.27 & 27.34 \\
\hline
\end{tabular}

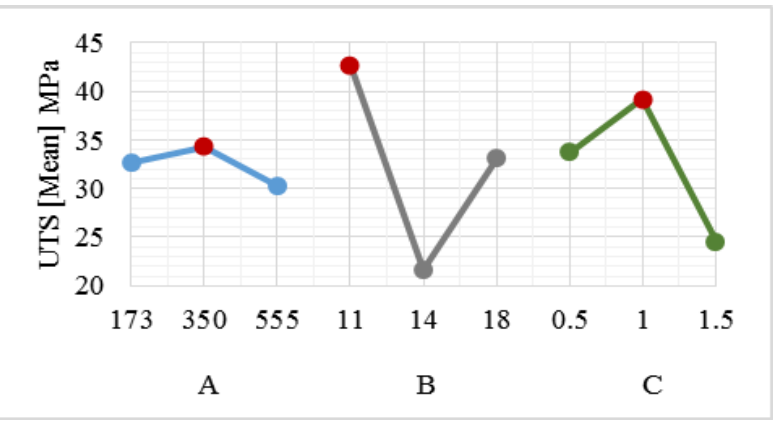

Figure. 2 The main effect plot for means.

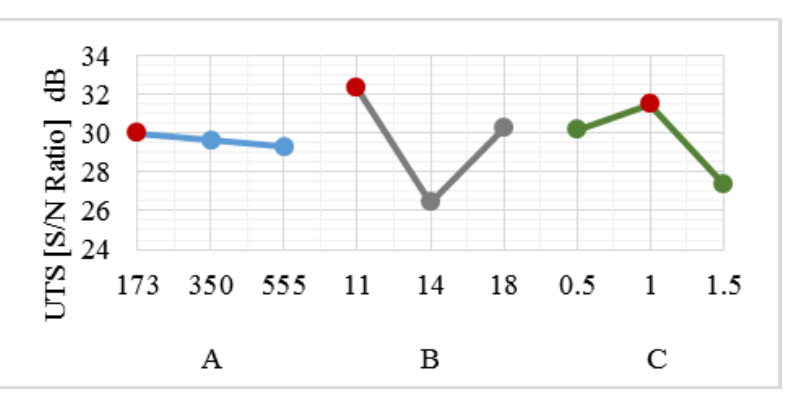

Figure. 3 The main effect plot for $\mathrm{S} / \mathrm{N}$ ratios.

Fig. 2 indicates that by reduction of pin offset to 0.5 $\mathrm{mm}$, the UTS of the joint will reduce. By approaching the 
Table 7. ANOVA results based on mean.

\begin{tabular}{cccccc}
\hline Source & $\begin{array}{c}\text { DO } \\
\text { F }\end{array}$ & SS & Mean sq. & F) Calculated & P\% \\
\hline A & 2 & 24.0128 & 12.0063 & 0.80208 & 2.30 \\
B & 2 & 670.2224 & 335.1112 & $\mathbf{2 2 . 3 8 7 0 6}$ & $\mathbf{6 4 . 3 0}$ \\
C & 2 & 333.1912 & 166.5956 & $\mathbf{1 1 . 1 2 9 3 9}$ & $\mathbf{3 1 . 9 6}$ \\
Error & 2 & 14.9689 & 7.4844 & & \\
Total & 8 & 1042.3954 & & & \\
\hline
\end{tabular}

Table 8. ANOVA results based on $\mathrm{S} / \mathrm{N}$ ratio.

\begin{tabular}{cccllc}
\hline Source & $\begin{array}{c}\text { DO } \\
\text { F }\end{array}$ & \multicolumn{1}{c}{ SS } & Mean sq. & F) Calculated & P\% \\
\hline A & 2 & 0.6546 & 0.3273 & 1.64658 & 0.79 \\
B & 2 & 54.1907 & 27.0953 & $\mathbf{1 3 6 . 3 0 9 5}$ & $\mathbf{6 5 . 7 4}$ \\
C & 2 & 27.3931 & 13.6965 & $\mathbf{6 8 . 9 0 3 8 2}$ & $\mathbf{3 3 . 2 3}$ \\
Error & 2 & 0.1987 & 0.0993 & & \\
Total & 8 & 82.4372 & & & \\
\hline
\end{tabular}

Table 9. F) Tabulated $_{\text {at }}$ DOF) $)_{\text {Factor }=2}$ and DOF $)_{\text {Error }=2 .}$.

\begin{tabular}{cccc}
\hline Confidence Level $\%$ & $90 \%$ & $95 \%$ & $99 \%$ \\
\hline F) Tabulated & 9.00 & 19.00 & 99.0 \\
\hline
\end{tabular}

tool to the brass interface, forging force and brass shoulder contact area will be increased resulting in more softening of brass that will produce continuous large fragments of brass in the stirring zone accompanied by cavities and cracks which reduce the UTS of the joint as shown in Fig. 4. But the all fractures of joints of $0.5 \mathrm{~mm}$ pin offset occurred in the interface. So the UTS might be decreased as a result of formation of IMCs layers at interface of the joints. Increasing forging force and brass - shoulder contact area leads to excessive heat generation resulting in forming brittle thick IMCs layer in the interface. Increasing the pin offset to $1.5 \mathrm{~mm}$, the jo int UTS will reduce as a result of low forged brass through aluminium side especially in the bottom of the joint. Consequently, the bottom of the joint interface is poor welded resulting in low UTS of the jo ints as shown in Fig. 5. According to the results, pin offset of $1 \mathrm{~mm}$ scored highest UTS as a result of providing sufficient forging force and optimum heat generation that decreased formation of IMCs layer at joint interface.

According to Fig. 2, at traverse speed of $11 \mathrm{~mm} / \mathrm{min}$, the UTS of the jo int reached its highest value as a result of sufficient of two factors accompanied with traverse speed; heat input rate and stirring time. Heat input rate is responsible for softening the metals and the stirring time is responsible for giving the metals a chance to mix together. The UTS of the joint decreased at the traverse speeds of $14 \mathrm{~mm} / \mathrm{min}$ and $18 \mathrm{~mm} / \mathrm{min}$ as a result of the heat input rate and stirring time are insufficient to softening the brass and make a good diffusion between brass and aluminium

The predicted value of response for the optimum setting (Run no. 4 setting) is calculated by the below formula:

$$
\mathrm{Y}_{\text {Predicted }}=\mathrm{Y}_{\text {Mean }}+\Sigma\left[\mathrm{Y}_{\mathrm{i}}-\mathrm{Y}_{\text {Mean }}\right]
$$

Where, $\mathrm{Y}_{\text {Mean }}$ is the total mean of response, $\mathrm{Y}_{\mathrm{i}}$ is the mean of response at optimal level of the factor, and $i$ is the factor number.

This predicted values is compared with experimental values (run no. 4) in table 10 and that indicates a high accuracy; $99.4 \%$ and $97.6 \%$.

Table 10. Predicted vs. Experimental results of the optimal setting.

\begin{tabular}{llll}
\hline & Prediction & Experimental & Accuracy \\
\hline Mean $(\mathrm{MPa})$ & 51.3182 & 52.5500 & $97.60 \%$ \\
S/N ratio & 34.1941 & 34.3949 & $99.41 \%$ \\
$(\mathrm{~dB})$ & & & \\
\hline
\end{tabular}

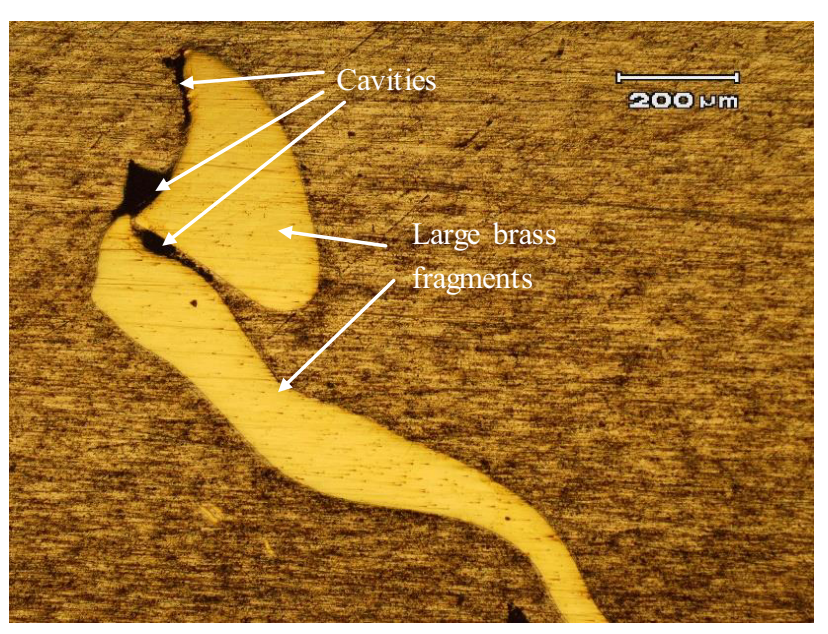

Figure. $4 \mathrm{OM}$ image of continuous large fragments of brass in aluminium SZ, the joint of run no. $6,0.5 \mathrm{~mm}$ pin offset.

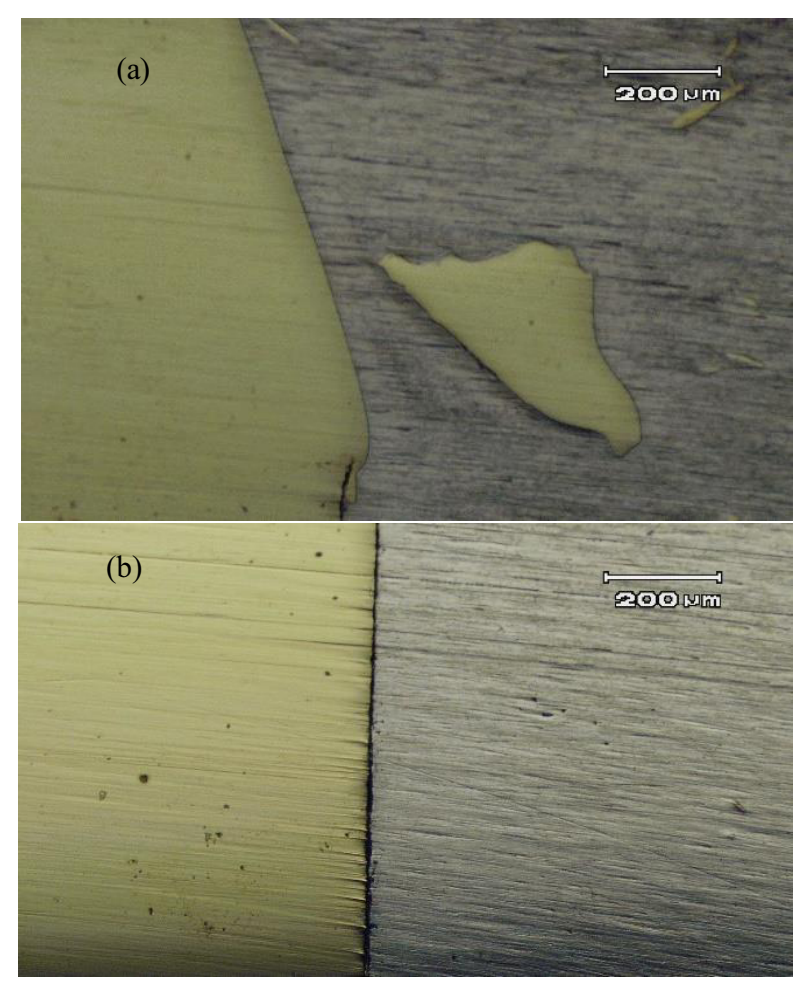

Figure.5 OM images of interface for joint of run no. 5, $1.5 \mathrm{~mm}$ pin offset (a) upper interface, and (b) lower interface. 


\subsection{Hardness test results}

Vickers hardness test is performed on the traverse cross section of the run no. 4 welded joint (optimum jo int). Various readings are gathered from different displacements from the interface on aluminium and brass sides along the middle of the traverse cross section. Fig. 6 shows the average hardness profile proceeded. Hardness profile reveals that hardness differs according to the weld ing zones on alumin ium side; stirring zone (SZ) and base metal have approximately the same hardness number. The thermal mechanical affected zone (TMAZ) and the heat affected zone (HAZ) have lower hardness number as a result of exposed to rapidly elevated temperature. Hardness number of brass in the HAZ is lower than the base metal as a result of exposing to elevated temperature.

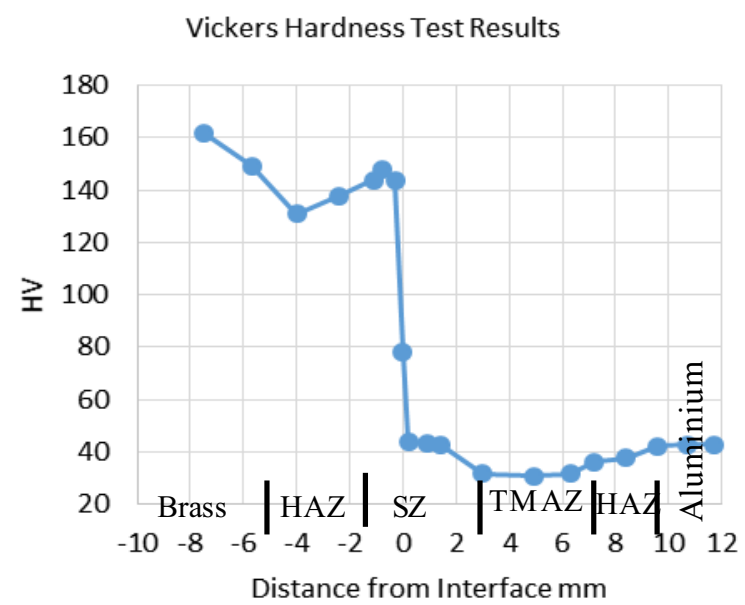

Figure. 6 Hardness profile along middle line of traverse cross section.

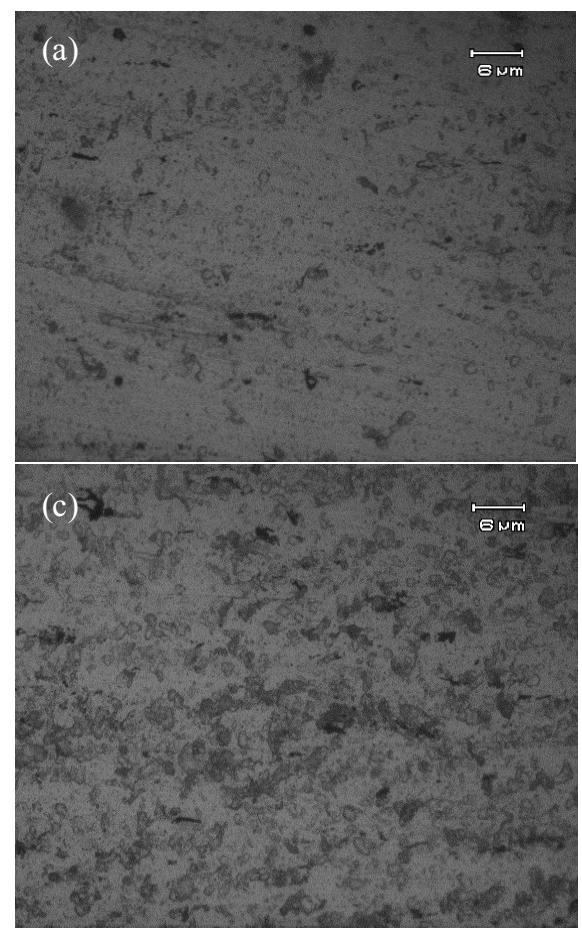

\subsection{Optical microscope examination}

A specimen of the joint produced by the optimum condition (4th run) is investigated by the optical microscope. Fig. 7 shows the microstructure of aluminium side in stirring zone, thermal mechanical affected zone, heat affected zone and aluminium base metal. The grains size differs in the different zones. Fig. 7a shows large aluminium grains in the base metal zone. Fig. $7 \mathrm{c}$ shows the smallest grain size that located in the thermal mechanical affected zone because exposing to rapidly elevated temperature. As the grains located in the heat affected zone are exposed to lower temperature than those in TMAZ, their size is larger than those in TMAZ as shown in Fig. 7c and Fig. 7d. Fig. 7b shows moderate grains size in the stirring zone as the tool pin forged the grains which are deformed and elongated to be larger than those in TMAZ and HAZ.

\subsection{SEM examination}

A specimen of the joint produced by the 4th run conditions is prepared for investigation under SEM. Fig. 8 shows that small brass particles exist in the stirring zone of aluminium but with very small ratio. A luminium is the dark side and brass is the bright side. Fig. 9 shows large brass fragments in the end of aluminium stirring zone accompanied with cavities. These large fragments are existed as a result of the brass being very hard and brittle. In tensile test, the fracture occurred in the interface at $52.5 \mathrm{MPa}$. That means the intermetallic compound that supposed to play the role of the bonding is very brittle and has tensile strength lower than the tensile strength of the stirring zone and HAZ [8]. Fig. 10 shows the interface investigation that reveals formation

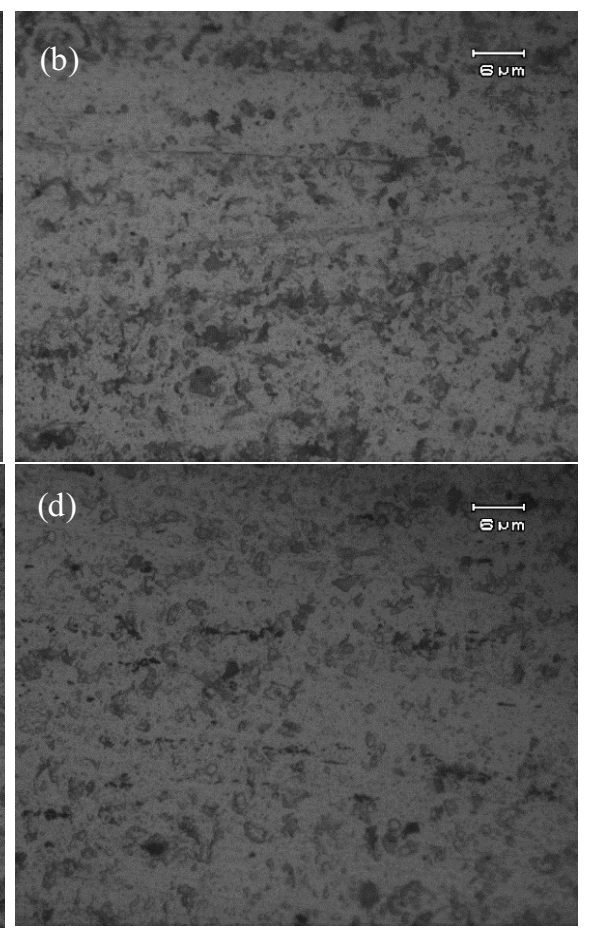

Figure. 7 Microstructure of various regions in aluminium side: (a) the base metal of aluminium, (b) the stir zone, (c) thermal mechanical affected zone, and (d) heat affected zone. 


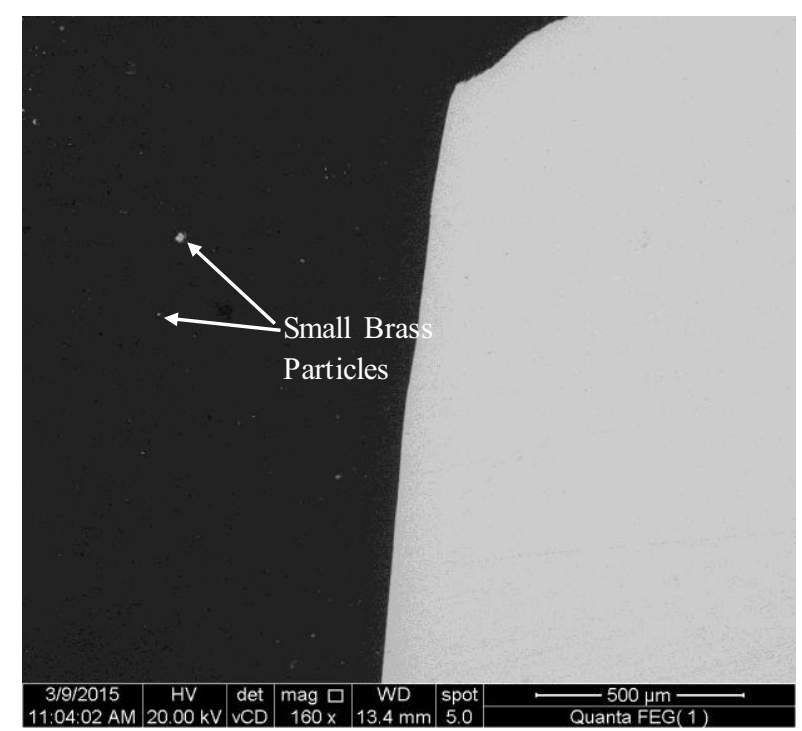

Figure. 8 SEM image of the joint of run no. 4.

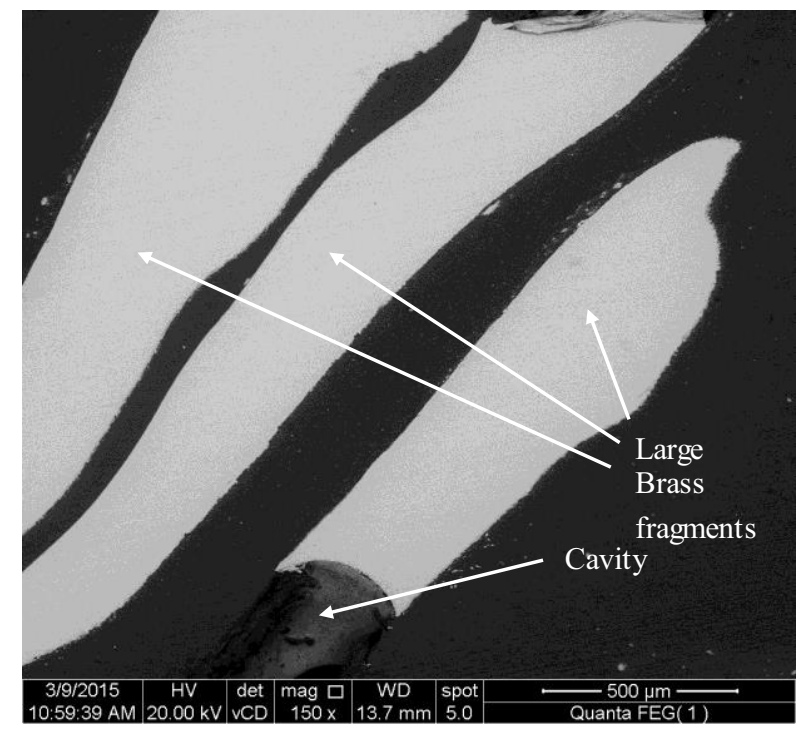

Figure. 9 SEM images of large brass particles in the end of the Al stirring zone.

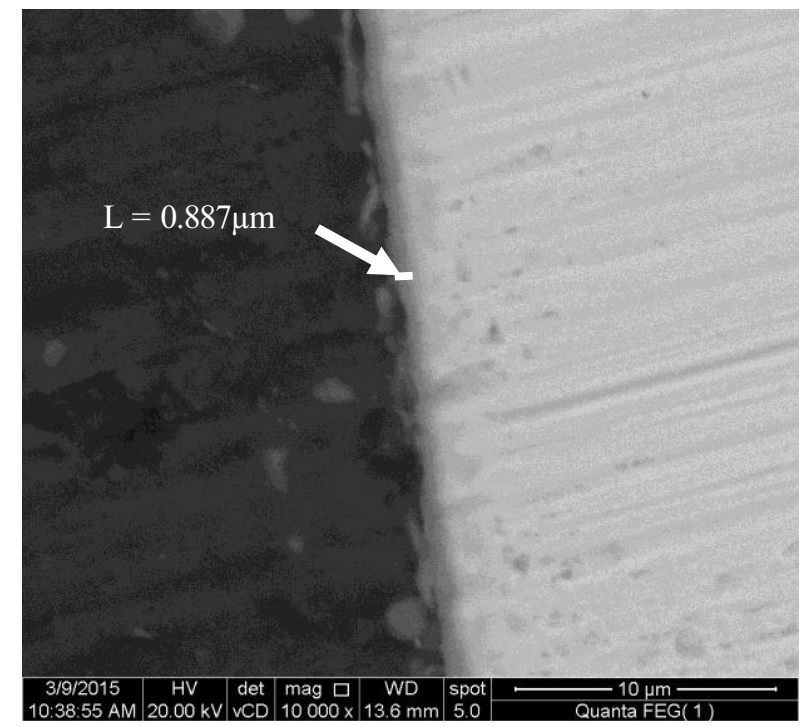

Figure. 10 Formation of intermetallic layer at interface of the joint. of intermetallic compound layer along the interface with thickness of $0.887 \mu \mathrm{m}$.

\section{Conclusions}

Experiments of FSW process using different levels of various parameters were conducted to produce butt joints of $5 \mathrm{~mm}$ thickness aluminium and brass $(\mathrm{CuZn} 30)$ plates. In summary, conclusions can be illustrated as follows:

- Within the selected ranges, the optimum levels of rotational speed, traverse speed and pin offset are $350 \mathrm{rpm}, 11 \mathrm{~mm}$ and $1 \mathrm{~mm}$ respectively with UTS = $52.55 \mathrm{MPa}(50 \%$ of Al base metal).

- Traverse speed and pin offset have high significant effects on the ultimate tensile strength of the joint and contribute about $65 \%$ and $33 \%$ respectively to overall contributions.

- Failure of optimum setting occurs in the interface because of forming brittle intermetallic compound in the interface.

\section{References}

1. R. S. Mishra, P. S. De, and N. Kumar, Friction Stir Welding and Processing Science and Engineering, 1st edition, Springer (2014).

2. M. Koilraj, V. Sundareswaran, S. Vijayan, and S. R. K. Rao, "Friction stir welding of dissimilar aluminum alloys AA2219 to AA5083 - Optimization of process parameters using Taguchi technique," Materials and Design, 42, pp. 1-7 (2012)

3. A. Es maeili, M. K. B. Givi, and H. R. Z. Rajani, " $A$ metallurgical and mechanical study on dissimilar Friction Stir welding of aluminum 1050 to brass (CuZn30)" Materials Science and Engineering: A, 528, pp. 7093-7102, (2011).

4. P. Xue, D. R. Ni, D. Wang, B. L. Xiao and Z. Y. Ma, "Effect of friction stir welding parameters on the microstructure and mechanical properties of the dissimilar $\mathrm{Al}-\mathrm{Cu}$ joints" Materials Science and Engineering: A, 528,pp. 4683-4689, (2011).

5. C. W. Tan, Z. G. Jiang, L. Q. Li, Y. B. Chen, and X. Y. Chen, "Microstructural evolution and mechanical properties of dissimilar Al-Cu joints produced by friction stir welding”, Materials and Design, 51, pp. 466-473, (2013).

6. P. J. Ross, Taguchi Techniques for Quality Engineering, 2nd edition, Mc Graw Hill Professional, (1996).

7. ASTM Standard E8/E8M, "Standard Test Methods for Tension Testing of Metallic Materials," ASTM International, West Conshohocken, PA, (2003).

8. P. Xue, B. L. Xiao, D. R. Ni and Z. Y. Ma, "Enhanced mechanical properties of friction stir welded dissimilar $\mathrm{Al}-\mathrm{Cu}$ joint by intermetallic compounds", Materials Science and Engineering: A, vol. 527, no. 21, pp. 5723-5727, (2010). 